\title{
Cone-Beam Computed Tomographic Evaluation of Maxillary Tuberosity after the Extraction of Maxillary Third Molars
}

\author{
Hussein Haleem Jasim ${ }^{1}$ \\ ${ }^{1}$ Department of Oral Diagnosis, College of Dentistry, University of Wasit, Kut City, Iraq.
}

\section{ABSTRACT}

\section{BACKGROUND}

Maxillary tuberosity is still one of the most important parts in the posterior maxilla, because of its role in the field of prosthetic dentistry, in particular in the improvement of the stability of upper dentures especially in the absence of abatement maxillary molars. The importance of the maxillary tuberosity to receive dental implants as in the case of the amount and the density of bone is critical in the posterior maxilla. In addition, the insertion of orthodontic mini screws in the maxillary tuberosity enables a good anchorage for the orthodontic movement of teeth to get the required space in the orthodontic treatment. The study aimed to evaluate the maxillary tuberosity status on CBCT images after the extraction of maxillary third molars.

\section{METHODS}

The cross-sectional comparative study included seventy patients aged between 25 and 45 years (regardless of gender). The patients were divided into group A and group B. Group A consisted of 35 patients who were found with absence of upper third molars which are missing congenitally. Group B consisted of 35 patients who were found with absence of upper-third molars, but due to the previous extraction for the period between one to three years after the extraction. A total of 120 CBCT maxillary tuberosity images (for both sides) were obtained from the two study groups. Evaluation of each maxillary tuberosity was done by linear measurement of length, width, and height of the maxillary tuberosity on these CBCT images.

\section{RESULTS}

The results showed that the mean dimensions of the maxillary tuberosity (width, length, and height) in Group A were $11.87 \mathrm{~mm}$ width, $10.17 \mathrm{~mm}$ length, and 11.22 $\mathrm{mm}$ height, while in Group B they were $9.93 \mathrm{~mm}$ width, $8.85 \mathrm{~mm}$ length and 8.78 $\mathrm{mm}$ height. Statistical analysis showed that the difference was significant for width and height measurements between the two groups, but it was not significant for the length measurements.

\section{CONCLUSIONS}

Extraction of the maxillary third molars leads to a significant reduction in most dimensions of the maxillary tuberosity.

\section{KEY WORDS}

Cone-Beam, Computed Tomography, Maxilla, Maxillary Tuberosity, Extraction, Third Molar
Corresponding Author: Dr. Hussein Haleem Jasim, University Lecturer, Department of Oral Diagnosis, College of Dentistry, University of Wasit, Kut City, Iraq.

E-mail: hhaleem@uowasit.edu.iq

DOI: $10.14260 / \mathrm{jemds} / 2020 / 440$

How to Cite This Article:

Jasim HH. Cone-beam computed tomographic evaluation of maxillary tuberosity after the extraction of maxillary third molars. J. Evolution Med. Dent. Sci. 2020;9(29):2019-2022, DOI: $10.14260 /$ jemds $/ 2020 / 440$

Submission 26-03-2020,

Peer Review 11-06-2020,

Acceptance 17-06-2020,

Published 20-07-2020.

Copyright (C) 2020 JEMDS. This is an open access article distributed under Creative Commons Attribution License [Attribution 4.0 International (CC BY 4.0)] 


\section{BACKGROUND}

Maxillary tuberosity is the terminal part of the maxilla on both sides and mostly contains the roots of third upper molars. The distal border of the maxillary tuberosity curved upward. For this reason, the maxillary tuberosity has clinical importance in the field of prosthetics and orthodontic dentistry, particularly it plays an important role in the retention of upper complete dentures in addition to the anchorage orthodontic of mini screws.

The maxillary artery to a great extent considers the main arterial supply to maxillary tuberosity after crossing beyond the lateral pterygoid anterior and oblique direction then into the pterygopalatine fossa.[1] Exactly before entering the "fossa", it releases the divisions of the posterior superior dental artery that encircle the maxillary tuberosity and finally go down in anterior and inferior direction. ${ }^{[2]}$

The divisions of the pterygoid venous plexus consider the main venous supply of the maxillary tuberosity, which may be situated inter-between the temporalis muscle and lateral pterygoids or between the medial and lateral pterygoids. The plexus is mostly differentiated in configuration, but is supposed to be enclosed around the maxillary tuberosity to guard it against blockage due to the mastication forces.[3]

The pterygopalatine fossa mostly contains veins that are too small in gauge within the path of the arteries. Some authors stated that the "sphenopalatine vein" could be recognized and emerging the sphenopalatine foramen and then crossing the pterygomaxillary fissure prior to linking the "pterygomaxillary plexus".[4] Apart from that, the venous drainage is significantly lost in the pterygopalatine fossa.[5] The tiny superficial end of the medial pterygoid derived from the maxillary tuberosity and the contiguous portion of the pyramidal process of the "palatine bone" directly above the maxillary tuberosity. The pterygoid venous anastomosis encloses or within the lateral pterygoid muscle.[6]

\section{Importance of Maxillary Tuberosity}

Maxillary tuberosity has a considerable role in the field of prosthetic dentistry, in particular, it precipitates in the improvement of the stability of upper dentures especially in the absence of the abutment maxillary molars. Any damage to the maxillary tuberosity such as fracture will cause impairment in prosthetic denture.[7]

Some authors stated that the maxillary tuberosity is appropriate for inserting and stabilizing implants for compensating the loss of teeth in the posterior part of maxilla especially when the amount of bone is not enough to insert the traditional dental implants and as well as to avoid the insertion of implants into the critical structures in this region as the maxillary sinus.[8] Many previous studies conducted that the dental implants showed a high success rate reached $94.63 \%$ in the region of maxillary tuberosity.[9]

Keeping anchorage during the orthodontic treatment still a challenging aim.[10,11] Many authors stated that the maxillary tuberosity was suitable for orthodontic anchorage and it is considered a good place for insertion of orthodontic mini screws.[11,12]

Insertion of the orthodontic mini screws at the region of the maxillary tuberosity provides an appropriate orthodontic anchorage, especially when planning for moving the anterior teeth with insufficient posterior upper teeth.[11,13] This will minimize damaging the roots of molars and neurovascular bundles. So in total, the orthodontic insertion of mini-screw in the maxillary tuberosity improves the orthodontic movement of teeth as retraction and "distalization" of upper teeth.[12][14][15] But others stated that the placement of the mini-screw at the region of maxillary tuberosity is not typical.[16]

\section{Complications of Maxillary Third-Molar Extraction}

Third molars are generally variable in the faces of their size and shape. Therefore, in the upper jaw, the complications of upper third molar extraction are possible to a considerable degree as oro-antral opening, displacing the roots or the entire tooth to the "antrum", fracture of the maxillary tuberosity or the alveolar process. The fracture of the maxillary tuberosity mostly occurs through the maxillary third molars and many factors could be responsible as dental anomalies, wide separated roots, chronic "periapical pathology", large sinuses with delicate walls, "ankyloses".[17] This type of fracture may be also occurred due to the decreased density of bone as in case of osteoporosis or due to some drugs or some habits, all of these may increase the possibility of this fracture. ${ }^{[18]}$ In addition, external factors may cause the fracture of the maxillary tuberosity as in the improper application of force on the surgical instruments or inappropriate support of alveolar bone during the extraction procedure.[19][20] Rarely, such complications can lead to profuse haemorrhage due to its proximity to large vessels. ${ }^{[5]}$ In addition, the oro-antral opening is also a usual problem following the maxillary tuberosity fracture. [7]

The incidence of maxillary tuberosity fracture due to third molar extraction reported to about 0.6.[21] Many studies showed that the maxillary tuberosity fracture is seldom during the extraction of the first or second maxillary molars in comparison to maxillary third molars. ${ }^{5]}[20][22-25]$

Maxillary tuberosity fractures can be recognized as small, moderate and severe maxillary tuberosity fracture and the latter is considered the most critical one because it is affected on some of the critical structures like blood vessels, muscles, and "pterygoid plate". The purpose of the current study was to evaluate the maxillary tuberosity status on CBCT images after the extraction of maxillary third molars.

\section{METHODS}

The study was carried out at the radiology department in the Teaching Hospital of Dentistry College-University of Wasit, Kut city-Iraq and in different dental centers of Baghdad cityIraq for taking cone-beam computed tomographic (CBCT) images, for the period between July 2019 to February 2020. A cross-sectional comparative design was involved in the current study. The sample size was determined according to the time allowed to carry out this study. A total of seventy patients were involved in the study aged between 25-45 years (regardless of gender) who were partitioned into two groups depending on the type of missing of maxillary third molars. 


\section{Group A}

Thirty-five patients who were found with the absence of upper third molars which are missing congenitally.

\section{Group B}

Thirty-five patients who were found with the absence of upper third molars but, due to previous extraction (complete healing cases) for the period between one to three years after the extraction.

\section{Exclusion Criteria}

- Impacted upper third molars.

- Maxillofacial malformations.

- Maxillofacial trauma.

- Systemic diseases.

- Patients who are taking drugs affecting the bone metabolism.

\section{Study Procedure}

A total of 120 CBCT maxillary tuberosity images (for both sides) got from the two study groups, 60 CBCT images for group A and 60 CBCT images for group $B$. The evaluation of each maxillary tuberosity was done on these CBCT images with linear measurement of length, width and height of the maxillary tuberosity as the following:

\section{Width}

It was measured on the axial view by measuring the vestibular-palatal distance of the maxillary tuberosity through the midway of measured maxillary tuberosity length at the level of $6 \mathrm{~mm}$ above the cementoenamel junction of the maxillary-second molar.

\section{Length}

It was measured on the sagittal view by measuring the anterior-posterior distance of the maxillary tuberosity started from the distal-vestibular root of the maxillarysecond molar and in point of $6 \mathrm{~mm}$ above the cementoenamel junction and extend in a straight line to the farthest point of the maxillary tuberosity in the opposite direction backward.

\section{Height}

It was measured on the sagittal view by measuring the inferior-superior distance of the maxillary tuberosity started from the alveolar crest downward (in a point of $6 \mathrm{~mm}$ distal to the cementoenamel junction of maxillary second molars on sagittal view) to the opposite point upward.

\section{Statistical Analysis}

The statistical analysis was done by using the Statistical Package for the Social Sciences software (version 19). A unpaired t-test used to compare the mean dimensions of the maxillary tuberosity in the mean between group $A$ and $B$. The level of significance was adjusted in 0.05 and it is evaluated as a significant if $\mathrm{p}$-value $<0.05$.

\section{RESULTS}

The results showed that the mean dimensions of the maxillary tuberosity (width, length, and height) in group A were: $11.87 \mathrm{~mm}$ width, $10.17 \mathrm{~mm}$ length, and $11.22 \mathrm{~mm}$ height, while in group B were: $9.93 \mathrm{~mm}$ width, $8.85 \mathrm{~mm}$ length and $8.78 \mathrm{~mm}$ height. The statistical analyses showed that the difference between the two groups was significant regarding the width measurements ( $\mathrm{p}$-value $=0.01$ ), and height measurements ( $p$-value $=0.02)$, but it was not significant for the length measurements $(p$-value $=0.06)$. Table 1.

\begin{tabular}{|c|c|c|c|c|c|c|}
\hline \multirow[b]{2}{*}{$\begin{array}{l}\text { Measurements } \\
(\mathrm{mm})\end{array}$} & \multicolumn{2}{|c|}{ Group A } & \multicolumn{2}{|c|}{ Group B } & \multirow[t]{2}{*}{ t-Test } & \multirow{2}{*}{$\begin{array}{l}\text { Significance Level } \\
\text { at } P \text {-Value }<0.05\end{array}$} \\
\hline & Mean & SD & Mean & SD & & \\
\hline Width & 11.87 & 4.44 & 9.93 & 3.65 & $\mathrm{t}=2.61$ & 0.010 (Significant) \\
\hline Length & 10.17 & 3.41 & 8.85 & 4.32 & $t=1.85$ & 0.065 (Not significant) \\
\hline Height & 11.22 & 4.52 & 8.78 & 7.12 & $t=2.24$ & 0.026 (Significant) \\
\hline Table 1. & own & he $M$ & $D i$ & cis & Max & iry Tuberosity \\
\hline
\end{tabular}

\section{DISCUSSION}

Many studies referred to the importance of the maxillary tuberosity in the field of dentistry. In a dental practice, the maxillary tuberosity has an important role in the retention and stability of the prosthetic upper denture. The maxillary tuberosity also considered a good substituted place for insertion of dental implant, especially in case of the insufficient bone amount in the posterior maxilla, as well as the maxillary tuberosity, has a good site for placing the orthodontic mini-screws to get the required anchorage particularly there is an insufficient number of maxillary molars that necessary for mesial shifting of anterior teeth. Some studies have been limited to monitoring the fracture of the maxillary tuberosity shortly following the extraction of maxillary third molars. Other studies observed and evaluated the treatment of these fractures.

By using of cone-beam computed tomography, the current study evaluated the status of the maxillary tuberosity in patients (Group A) with previous surgical extracted maxillary third molars (complete healing cases) by measuring of the maxillary tuberosity dimensions (length, width, and height) on cone-beam computed tomographic images and comparing these measurements with the dimensions of the maxillary tuberosity in patients (Group B) with the congenital absence of maxillary third molars.

The current study showed that the mean dimensions of the maxillary tuberosity in group A were: $11.87 \mathrm{~mm}$ width, $10.17 \mathrm{~mm}$ length, and $11.22 \mathrm{~mm}$ height, while in group B were: $9.93 \mathrm{~mm}$ width, $8.85 \mathrm{~mm}$ length and $8.78 \mathrm{~mm}$ height. The difference was significant for the width and height measurements between the two groups, but it was not significant for the length measurements.

It is clear from the results of the current study that there was a significant decrease in the measurements of maxillary tuberosity width and height in group B in comparison with group $A$, as well as the study showed a non-significant decrease in length measurements when compared to group $\mathrm{A}$. 
Manzanera et al observed the dimensions of the maxillary tuberosity and their correlation with age and gender but under normal conditions. They measured the dimensions of maxillary tuberosity in multiple levels and they found that the means of length, width, and height according to these levels were ranged from $12.24 \mathrm{~mm}$ to $9.11 \mathrm{~mm}$ in width, 9.42 $\mathrm{mm}$ to $11.25 \mathrm{~mm}$ in length and $10.06 \mathrm{~mm}$ to $11.91 \mathrm{~mm}$ in height.[26]

Some studies evaluated the maxillary tuberosity in dry skulls and the mean width was $21.1 \mathrm{~mm}$ and the mean height was $4.89 \mathrm{~mm}$ in one study.[27] While the mean width was $20.38 \mathrm{~mm}$ and the mean height was $7.45 \mathrm{~mm}$ in another study.[28]

\section{CONCLUSIONS}

Extraction of maxillary third molars causes a significant reduction to the maxillary tuberosity's width and height.

My special thanks to all staff of Department of Radiology, where the study was conducted.

\section{REFERENCES}

[1] Lang J. Clinical anatomy of the masticatory apparatus and peripharyngeal spaces. New York: Thieme Medical Publishers Inc., 1995.

[2] Carter EF. The bucco-gingival branch of the posterior superior alveolar artery: a source of haematomata when injecting in the maxilla. Aust Dent J 1983;28(4):197-201.

[3] Sicher H, DuBrul EL. Oral anatomy. $7^{\text {th }}$ edn. St Louis: CV Mosby 1982: p. 351-76.

[4] Pearson BW, MacKenzie RG, Goodman WS. The anatomical basis of transantral ligation of the maxillary artery in severe epistaxis. Laryngoscope 1969;79(5):969-84.

[5] Bertram AR, Rao ACA, Akbiyik KM, et al. Maxillary tuberosity fracture: a life-threatening haemorrhage following simple exodontia. Aust Dent J 2011;56(2):2125.

[6] Berkovitz BKB, Moxham BJ. A textbook of head and neck anatomy. Barcelona: Wolfe Medical Publications Ltd., 1988: p. 174-6.

[7] Olborska A, Osica P, Janas A. Iatrogenic fracture of the maxillary tuberosity - a case report. Journal of Education, Health and Sport 2017;7(12):155-68.

[8] Yamaura T, Abe S, Tamatsu Y, et al. Anatomical study of the maxillary tuberosity in Japanese men. Bull Tokyo Dent Coll 1998;39(4):287-92.

[9] Lopes LF, da Silva VF, Santiago JF, et al. Placement of dental implants in the maxillary tuberosity: a systematic review. Int J Oral Maxillofac Surg 2015;44(2):229-38.

[10] Ganzer N, Feldmann I, Petrén S, et al. A cost-effectiveness analysis of anchorage reinforcement with miniscrews and molar blocks in adolescents: a randomized controlled trial. Eur J Orthod 2019;41(2):180-7.
[11] Garalda VJS. Simultaneous intrusion and distalization using miniscrews in the maxillary tuberosity. J Clin Orthod 2016;50(10):605-12.

[12] Nakao N, Kitaura H, Koga Y, et al. Application of a miniscrew at the maxillary tubercle for treatment of maxillary protrusion. Orthodontic Waves 2008;67(2):7280.

[13] Huang LH, Shotwell JL, Wang HL. Dental implants for orthodontic anchorage. Am J Orthod Dentofacial Orthop 2005;127(6):713-22.

[14] Venkateswaran S, Rao V, Krishnaswamy NR. En-masse retraction using skeletal anchorage in the tuberosity and retromolar region. J Clin Orthod 2011;45(5):268-73, quiz 288.

[15] Venkateswaran S, George AM, Anand MK, et al. Skeletal anchorage using mini-implants in the maxillary tuberosity region. J Indian Orthod Soc 2013;47(4):21724.

[16] Poggio PM, Incorvati C, Velo S, et al. "Safe zones": a guide for miniscrew positioning in the maxillary and mandibular arch. Angle Orthod 2006;76(2):191-7.

[17] Thirumurugan K, Munzanoor RRB, Prasad GA, et al. Maxillary tuberosity fracture and subconjunctival hemorrhage following extraction of maxillary third molar. J Nat Sci Biol Med 2013;4(1):242-5.

[18] Tay ZW, Zakaria SS, Zamhari AK, et al. Dentoalveolar fracture: a complication of extraction of upper left first molar. Clin Case Rep 2018;6(11):2096-8.

[19] Norman JE, Cannon PD. Fracture of the maxillary tuberosity. Oral Surg Oral Med Oral Pathol 1967;24(4):459-67.

[20] Polat HB, Ay S, Kara MI. Maxillary tuberosity fracture associated with first molar extraction: a case report. Eur J Dent 2007;1(4):256-9.

[21] Chiapasco M, De Cicco L, Marrone G. Side effects and complications associated with third molar surgery. Oral Surg Oral Med Oral Pathol 1993;76(4):412-20.

[22] Shah N, Bridgman JB. An extraction complicated by lateral and medial pterygoid tethering of a fractured maxillary tuberosity. Br Dent J 2005;198(9):543-4.

[23] Chrcanovic BR, Freire-Maia B. Considerations of maxillary tuberosity fractures during extraction of upper molars: a literature review. Dent Traumatol 2011;27(5):393-8

[24] Ngeow WC. Management of the fractured maxillary tuberosity: an alternative method. Quintessence Int 1998;29(3):189-90.

[25] Altug HA, Sahin S, Sencimen M, et al. Extraction of upper first molar resulting in fracture of maxillary tuberosity. Dent Traumatol 2009;25(1):e1-2.

[26] Manzanera E, Llorca P, Manzanera D, et al. Anatomical study of the maxillary tuberosity using cone beam computed tomography. Oral Radiol 2018;34(1):56-65.

[27] Cheung LK, Fung SC, Li T, et al. Posterior maxillary anatomy: implications for Le Fort I osteotomy. Int J Oral Maxillofac Surg 1998;27(5):346-51.

[28] Apinhasmit W, Chompoopong S, Methathrathip D, et al. Clinical anatomy of the posterior maxilla pertaining to Le Fort I osteotomy in Thais. Clin Anat 2005;18(5):323-9. 